published in: Acta Materialia 51 (2010) 3690-3700

\title{
The influence of indenter tip rounding on the indentation size effect
}

\author{
Xiao Guang Qiao, Marco J. Starink, Nong Gao \\ Materials Research Group, School of Engineering Sciences, University of \\ Southampton, Southampton SO171BJ, UK
}

\begin{abstract}
A m odel was develope $d$ to interp ret the indentation size eff ect (ISE). The $\mathrm{m}$ odel considers the tip wear effect, causing a rounded tip, th e plastic zone size and various strengthening contributions, including geom etrically ne cessary dislocations, preexisting statistically stored dislocations and grain size. It is shown that the shape of the worn tip can be effectively determ ined through calibration experim ents. The model is applied to predict dislocati on densities, and shows a good correspondence with published data on dislocation densities in copper single crystals. Predicted ISE is shown to be in good correspondence with published data on a range of metals, and an improvement over existing models is demonstrated.
\end{abstract}

Key words: Ultra fine-grained (UFG) alum inium, nanoindentation, geom etrically necessary dislocations, tip rounding effect

\section{Introduction}

\subsection{General approach aims}

The influence of strain gradient effects needs to be include $d$ in the formulation of the constitutive behaviour of $\mathrm{m}$ aterials at micro-scale $[1,2]$ and a number of $\mathrm{g}$ radient plasticity models accounting for these effects have been proposed (see e.g. [3,4]). One example of an experim ent revealing the stra in gradient effect is nanoindentation, in which the hardness detected has been shown to depend on the indent size, which is the so called in dentation size effect (ISE) [5]. The I SE is generally explained using the so-called ' $m$ echanism-based g radient $p$ lasticity theo ry' in which geom etrically necessary dislocations (GNDs) [6,7,8] gene rated in the plastic zone underneath the indent due to strain gradients play a key part. Decreasing in dentation size gives rise to 
an increasing density of GNDs, and, hence, an increasing hardness. Understanding of the ISE is crucial to developm ent of FE models that incorporate GNDs. Thus, the ISE has received intense interest and a range of models have been presented to analyse the measured hardness vs indentation depth relation.

Published work on the ISE show $\mathrm{s}$ that the existing formulations of m odels lo ose accuracy in predicting $m$ easured nanoinde ntation hardn ess for indentation depth below about $150 \mathrm{~nm}$ whilst some approach es need a large num ber of fittable parameters to account for $\mathrm{m}$ easured na noindentation hardness (section 1.2). This range of differing models can lead to doubts on the range of validity of the theoretical approaches. The objective of the present work is to show that existing and new data on the indentation size effect can be mode lled with improved accuracy and down to a smaller indentation depth using a $\mathrm{m}$ odel in which we incorporate an accurat e description of a blunted inde nter tip and various additiona 1 strengthening effects, all within the $\mathrm{m}$ echanism-based gradient $\mathrm{pl}$ asticity theory. The $\mathrm{m}$ odel is based on analytical equations, and is hence computationally highly efficient.

\subsection{Existing models for the ISE}

In the Nix-Gao m odel [9], the GNDs are a ssumed to distribute in the he misphere underneath the indenter with radius of $a_{\mathrm{c}}$ (projected con tact radius), and the averag e density of GNDs, $\rho^{N-G}{ }_{G N B}$, is given by,

$\rho_{G N D}^{N-G}=\frac{3}{2 b h} \tan ^{2} \theta_{0}$

where $b$ is the Burgers vector, $h$ is the indentation depth and $\theta_{0}$ is the angle of conical indent surface to the sample planar surface. From this, it follows that the indentation hardness is only related to the indentation depth. This approach leads to the often applied equation [9]:

$$
\frac{H}{H_{0}}=\sqrt{1+\frac{h^{*}}{h}}
$$

where $H$ is the indentation hardness, $\quad h$ is the indentation depth, $h^{*}$ and $H_{0}$ are constants depending on the $\mathrm{m}$ aterial and can be obtain ed by fitting the experimental results. The Nix-Gao m odel provided a good fit to the m easured ISE of (111) single crystal copper, cold worked polycrystalline copper, (100) single crystal silver and (110) single crystal silver $\mathrm{w}$ ith the indentation depth larg er than $150 \mathrm{~nm}$ [9]. Tw o parameter models, such as the $\mathrm{N}$ ix-Gao model, show in creasing deviation from 
measured nanoindentation hardness at low in dentation depths (typically lower than $150 \mathrm{~nm})[9,10,11,12,13]$. In attem pts to clarify these deviations, a num ber of modifications of the model have been proposed, see e.g. [14,15]. All of these methods provided so me improvements, but often at the expense of introducing new fittable parameters. For instance Chicot [14] cons idered the nano-inde ntation hardness and micro-indentation hardness sepa rately, i.e. using different $H_{0}$ and $h^{*}$ values when predicting the nano-indentation hardness and micro-indentation hardness. Swadener et al. [10] assum ed the indentation depth is proportional to the conta ct $r$ adius to the power $n(n>1)$. The GND density was then calc ulated following the Nix-Gao m odel. Both of these m odels showed improvements as compared to the Nix-Gao m odel, but regions of poor fit to data rem ained. Abu Al -Aub [15] assum ed the GND and statistically stored dislocation (SSD) dens ity should be coupled by a power and also considered the strengthening contribution by intrinsic stress. This provides:

$$
\left(\frac{H-H_{\mathrm{y}}}{H_{0}-H_{\mathrm{y}}}\right)^{\beta}=1+\left(\frac{h^{*}}{h_{\mathrm{c}}}\right)^{\beta / 2} \quad \text { Eq. 3) }
$$

where $H_{\mathrm{y}}$ is the hardness contribution by the intrinsic stress, $\quad \beta$ is a constan $\mathrm{t}$ and determined as $0.77-1.2$ by $\mathrm{f}$ itting. The latter equation provides a better predic tion of the nanoind entation hardness but $\mathrm{s}$ till can not a ccurately predict the na noindentation hardness at very low indentation de pth (s ee section 4). Feng and Nix [12] incorporated $f$ in Nix-Gao m odel and assum ed $f$ follows an exponential relation with indentation depth $h$ introducing two new coefficients. Therefore, there are four fittable parameters in the predicting function, which adds extensive flexibility allowing fitting to virtually any dataset.

Huang et al. [16] studied the ISE using the continuum theory of $m$ echanism-based stain g radient plas ticity (CMSG) [ 17] ba sed on Taylor dislocation $\mathrm{m}$ odel by finite element (FE) m ethod. This work showed a good correlation with the ISE of several metals, but it fails to predict the nanoindentation hardness with indentation depth less than $150 \mathrm{~nm}$ because the tip rounding effect has not been considered.

In the pres ent work, we consider th at the $\mathrm{m}$ ain cause $\mathrm{f}$ or deviations $\mathrm{f}$ rom existing models is due to deviation from the ideal pyramid shape of the tip. This tip rounding can be due to wear and localised nanoscale fr acture at the tip, which in practice will be unavoidable. A rounded ti $p$ has been considered in som e works [10, 18], whi ch provide an improved fit to experiments, but still failed to fully explain deviations. 
Huang, Hwang, Nix and co-workers [19,20, 21] studied the tip rounding effect using CMSG theory in an FE analysis . They predicted tha $t$ the ind entation hardn ess increases with the incr easing ind entation depth when the indentation depth is lower than the height of the rounded tip; then de creases with the incr easing indentation depth when the indentation depth is larger than the height of the rounded tip. A test of the model reported in [21], using hardness data of $\mathrm{MgO}$, indicated that their model of the tip rounding effect alone can not explain these experimental results.

Apart from the tip rad ius effect, adjust ing th e assum ed size of the plastic zon e underneath the indent has also been consid ered in several works to provide a $\mathrm{m}$ ore accurate hardness prediction. Feng and Nix [12] and Durst et al [22,23] considered the radius of the plastic zo ne under the indent is $f$ tim es larg er than the radius of the contacted area. Feng and Nix [12] assum ed the $f$ value is continuous factor varying with the contact depth in an exponential function, whilst Durst et al $[22,23]$ assumed $f$ is fixed for specific $\mathrm{m}$ aterials. The $\mathrm{m}$ odified models provide good predictions for different materials at the expense of using a range of fitting parameters; with $f$ values from 1 to 2.6 .

\section{Model of indentation size effect for blunted tip.}

\subsection{Generation of GNDs.}

In this s ection we will provide an im proved calculation of the ISE in the case of a non-perfect (rounded) indenter tip, avoiding the $\mathrm{m}$ any approximations involved in [18]. W e will cons ider a $\mathrm{r}$ ounded tip with fixed radius. It can be considered as comprised of two parts: a spherical cap and a conical frustum (see Fig. 1). W e will take $a_{\mathrm{pz}}=f a_{\mathrm{c}}$, where $f>1[12,22], a_{\mathrm{pz}}$ and $a_{\mathrm{c}}$ are the radius of the plastic zone and the contact area. With reference to Fig. 1 it can be seen that:

$$
\begin{aligned}
& \begin{array}{ll}
h=h_{1}+h_{2} & \text { Eq. 4) }
\end{array}
\end{aligned}
$$

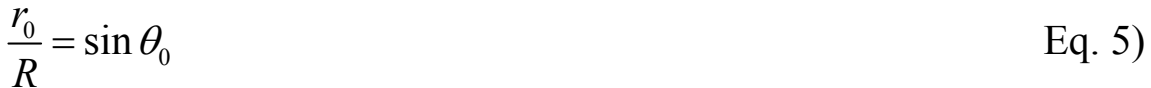

$$
\begin{aligned}
& h_{2}=R-\sqrt{R^{2}-r_{0}^{2}} \quad \text { Eq. 6) } \\
& \begin{array}{lll}
\tan \theta=\frac{b}{S} & \text { Eq. 7) }
\end{array} \\
& \begin{array}{ll}
\tan \theta_{0}=\frac{h_{1}}{a_{c}-r_{0}} & \text { Eq. 8) }
\end{array}
\end{aligned}
$$


where $h$ is indentation depth, $h_{2}$ is the height of the spherical cap, $r_{0}$ is the radius of the bottom surface of the spherical cap as well as th e top surface of the conical frustum, $S$ is the averag e horizon tal distance of dislocation s, $\theta_{0}$ is the an gle of the conical surface and the sample top surface (value of which is constan $\mathrm{t}$ ) and $\theta$ is the angle of the spherical surface and the sample top surface (value of which is variable).
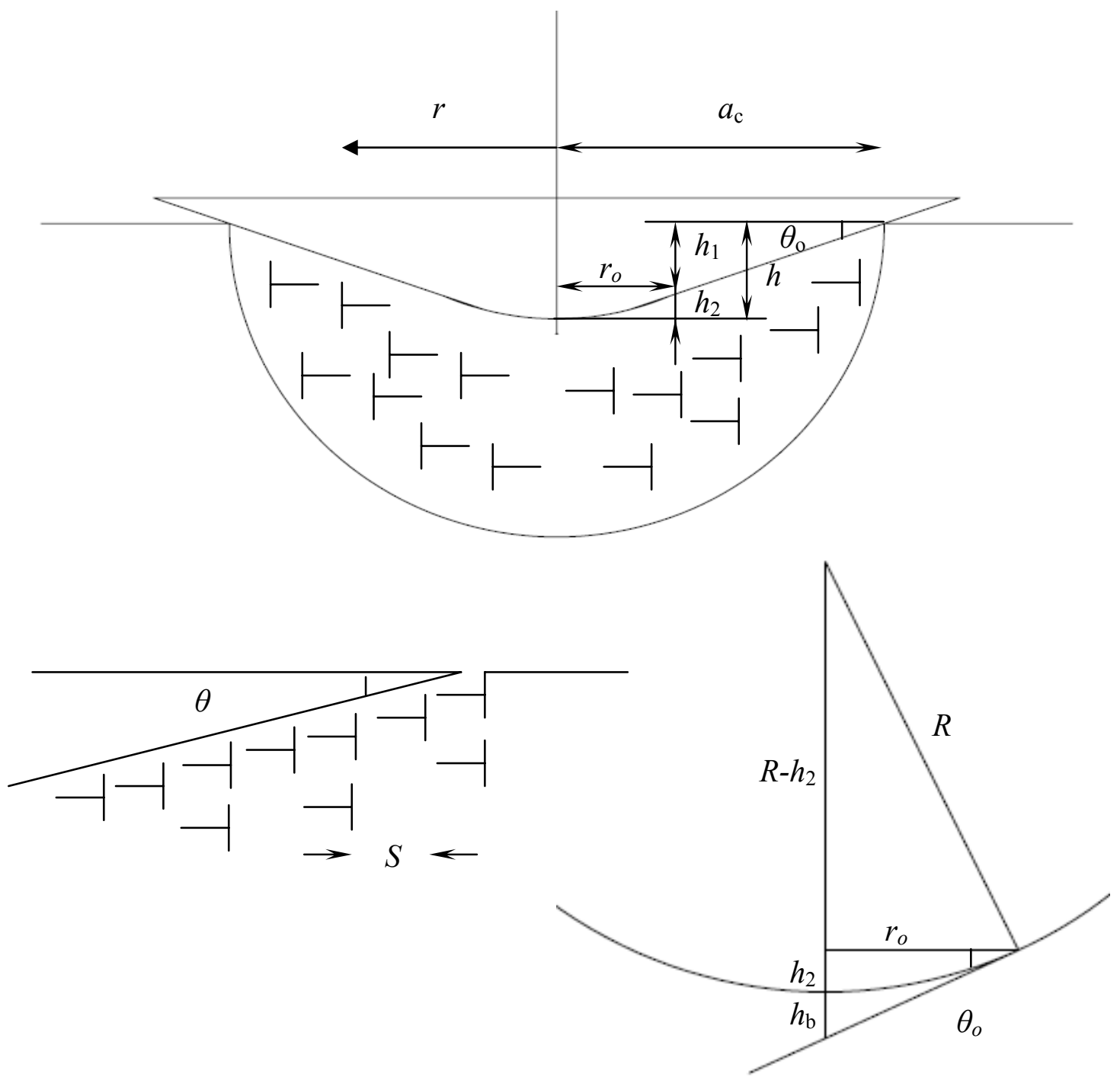

Fig. 1 Schematic sketch of distribution of GNDs underneath the rounded conical tip [9]

From Eq. 4 to Eq. 8 follows,

$r_{0}^{2}-\frac{2 h_{2}}{\sin \theta_{0}} r_{0}+h_{2}^{2}=0$

Solving the latter equation and taking into account that $\frac{r_{0}}{h_{2}}>\cot \theta_{0} \quad$ (see Fig. 1) provides: 
$r_{0}=\frac{1+\cos \theta_{0}}{\sin \theta_{0}} h_{2}$

Substituting Eq. 10 to Eq. 8 provides:

$$
\begin{aligned}
& a_{c}=\frac{h_{1}}{\tan \theta_{0}}+r_{0}=\frac{h_{1}}{\tan \theta_{0}}+\frac{1+\cos \theta_{0}}{\sin \theta_{0}} h_{2}=h \cot \theta_{0}+h_{2} / \sin \theta_{0} \\
& R=\frac{r_{0}}{\sin \theta_{0}}=\frac{1+\cos \theta_{0}}{\sin ^{2} \theta_{0}} h_{2}=\frac{1}{1-\cos \theta_{0}} h_{2} \\
& h_{\mathrm{b}}=\frac{1}{\cos \theta_{0}} h_{2}
\end{aligned}
$$

where $h_{\mathrm{b}}$ is blunting distance (see Fig. 1). The total length of GND $\lambda(h)$ comprises of two parts

$$
\lambda(h)=\lambda_{1}\left(h_{1}\right)+\lambda_{2}\left(h_{2}\right)
$$

where $\lambda_{1}\left(h_{1}\right)$ stands for the length of GND undern eath the conical frustum while the $\lambda_{2}\left(h_{2}\right)$ stands for the length of GND underneath the spherical cap. $\lambda_{1}\left(h_{1}\right)$ and $\lambda_{2}\left(h_{2}\right)$ are given by:

$$
\begin{aligned}
& \lambda_{1}=\int_{r_{0}}^{a} 2 \pi r \frac{d r}{S}=\int_{r_{0}}^{a} 2 \pi r \frac{\tan \theta_{0}}{b} d r=\frac{\pi \tan \theta_{0}}{b}\left(a_{c}{ }^{2}-r_{0}{ }^{2}\right) \\
& \lambda_{2}=\int_{0}^{r_{0}} 2 \pi r \frac{d r}{S}=\int_{0}^{r_{0}} 2 \pi r \frac{\tan \theta}{b} d r=\int_{0}^{\theta_{0}} \frac{2 \pi R^{2} \sin ^{2} \theta}{b} d \theta=\frac{\pi R^{2}}{b}\left(\theta_{0}-\sin \theta_{0} \cos \theta_{0}\right)
\end{aligned}
$$

The radius of the plastic zone is taken as $f$ tim es of the contact rad ius, therefore, $V=\frac{2}{3} \pi f^{3} a_{c}{ }^{3}$. Substituting Eq. 10 Eq. 16 into $\rho=\frac{\lambda(h)}{V}$, provides the GND density, $\rho_{G N D}$

$\rho_{G N D}=\frac{3 \tan ^{2} \theta_{0}}{2 b f^{3}\left(h+h_{\mathrm{b}}\right)}\left(1+\frac{\left(\theta_{0}-\tan \theta_{0}\right) \sin \theta_{0} \cos \theta_{0}}{\left(1-\cos \theta_{0}\right)^{2}} \cdot \frac{h_{\mathrm{b}}{ }^{2}}{\left(h+h_{\mathrm{b}}\right)^{2}}\right)$

In Eq. 17, $\theta_{0}$ is $19.7^{\circ}$ for a Berkovich tip, which can be obtained from indent shape parameters. The value of $h_{\mathrm{b}}$ can be obtained by $\mathrm{m}$ easurement using atom ic force microscope (AFM) or scanning electron $m$ icroscope (SEM). Alternatively, it can also be obtain ed by $f$ itting the ind ent shape cor rection equ ation. The contac $t$ ar ea according to current model is,

$$
A_{\mathrm{c}}=\pi a_{\mathrm{c}}^{2}=\frac{\pi}{\tan ^{2} \theta_{0}}\left(h+h_{\mathrm{b}}\right)^{2}
$$


The above expressions are valid for $h>h_{2}$. The corresponding equations for $h<h_{2}$, i.e. for a purely spherical indent, are given in the appendix.

In contrast to this, Alkorta et al [18] made a range of approximations and suggested:

$$
\begin{aligned}
& A_{\mathrm{c}}=\pi a^{2}=\pi \tan ^{2} \phi \cdot h_{\mathrm{f}}^{2}+2 \pi R h_{\mathrm{f}} \\
& \text { i.e, } \\
& a=\tan \phi \sqrt{h_{f}^{2}+\frac{2 R}{\tan ^{2} \phi} h_{f}}
\end{aligned}
$$

where $a$ is the radius of contact area, $\phi$ is complementary to $\theta_{0}, h_{\mathrm{f}}$ is the depth and $R$ is the radius of rounded tip.

\subsection{Strength model}

The Nix-Gao model and most of its derivatives [9,10,12] only consider the dislocation strengthening, whilst other strengthening $\mathrm{c}$ ontributions remain unspecified and are part of the f ittable $\mathrm{p}$ arameter $H_{\mathrm{o}}$. In the current stu dy, the grain boundary strengthening including s ubgrain boundary and grain bound ary and remaining $\mathrm{m}$ inor strengthening contribution are also considered as well as the dislocation strengthening, using the expression $[24,25,26]$ :

$\sigma_{\mathrm{y}}=\Delta \sigma_{\mathrm{gb}}+M \tau_{\mathrm{tot}}=\Delta \sigma_{\mathrm{gb}}+M\left[\Delta \tau_{0}+\Delta \tau_{\mathrm{ss}}+\left(\Delta \tau_{\mathrm{D}}^{2}+\Delta \tau_{\mathrm{ppt}}{ }^{2}\right)^{1 / 2}\right]$

where $\sigma_{\mathrm{y}}$ is yield strength, $\Delta \sigma_{\mathrm{gb}}$ is the streng thening due to the presence of grain or subgrain boundaries, $M$ is a factor often referred to as the Taylor facto r. $\tau_{\text {tot }}$ is the critical resolved shear stress (CRSS) of the grains. The hardness is expressed as

$$
H=C \sigma_{\mathrm{y}} \quad \text { Eq. 22) }
$$

where $C$ is a constan t. To sim plify the expre ssions, the contributions to the yield strength by intrins ic C RSS ( $\left.\tau_{0}\right)$, solid solu tion s trengthening $\left(\tau_{\mathrm{S}}\right)$ are tak en as a constant term $\sigma_{0}$, whilst at this stage we will avoid precipitation hardened materials (ie. $\Delta \tau_{\mathrm{ppt}}=0$ ). The value of constant $C$ is generally taken a $\mathrm{s} 3$ in the lite rature for conventional hardness test. However, the nanoindentation hardness is generally 10$30 \%$ higher than the Vickers hardness for many metals even using a large indentation depth to avoid the ISE [ 27]. The differ ence between nanoindentation and Vickers hardness is partly due to the former being defined by project ed area while the latter is defined by contact area, which would $i$ nduce a difference of about a factor $1 / \sin \left(136^{\circ} / 2\right)=1.08$ (the vertex angle of Vickers tip is $136^{\circ}$ ). Therefore, we allow the 
proportionality constant $C_{2}$ for nanoindentation hardness to be som ewhat larger that that for Vickers hardness (see also section 2.3), ie.:

$$
\begin{aligned}
& H \mathrm{v}=C_{1} \sigma_{\mathrm{y}}=C_{1}\left[\sigma_{0}+\Delta \sigma_{\mathrm{GB}}+M \alpha_{1} G b \sqrt{\rho_{\mathrm{SSD}}}\right] \\
& H \mathrm{n}=C_{2} \sigma_{\mathrm{y}}=C_{2}\left[\sigma_{0}+\Delta \sigma_{\mathrm{GB}}+M \alpha_{1} G b \sqrt{\rho_{\mathrm{GND}}+\rho_{\mathrm{SSD}}}\right]
\end{aligned}
$$

where $H \mathrm{v}$ is the Vickers hardness, $\quad H \mathrm{n}$ is the nanoindentation hardness, $\quad \alpha_{1}$ is a constant (about 0.3 [7]), $G$ is the shear modulus of Al.

\subsection{Model predictions}

To evaluate the presen $\mathrm{t}$ m odel and com pare it to other models, the GND density predicted by the Nix-Gao m odel, Alkorta et al [18] m odel and the current model are calculated and presen ted in Fig. 2 ( $b$ is taken as $0.286 \mathrm{~nm}$, the value for Al). F ig. 2 shows that the current model (taking $h_{2}=110 \mathrm{~nm}$ ) predicts a m uch milder ISE than the Nix-Gao m odel. For large indentation depth (typically $h>400 \mathrm{~nm}$ ) the GND density predictions in current $\mathrm{m}$ odel and Nix-Gao m odel with $f=1.76$ converge. The current model predicts an ISE that is clearly very different from the Alkorta et al [18] model. This is due to the approximations made in the latter model.

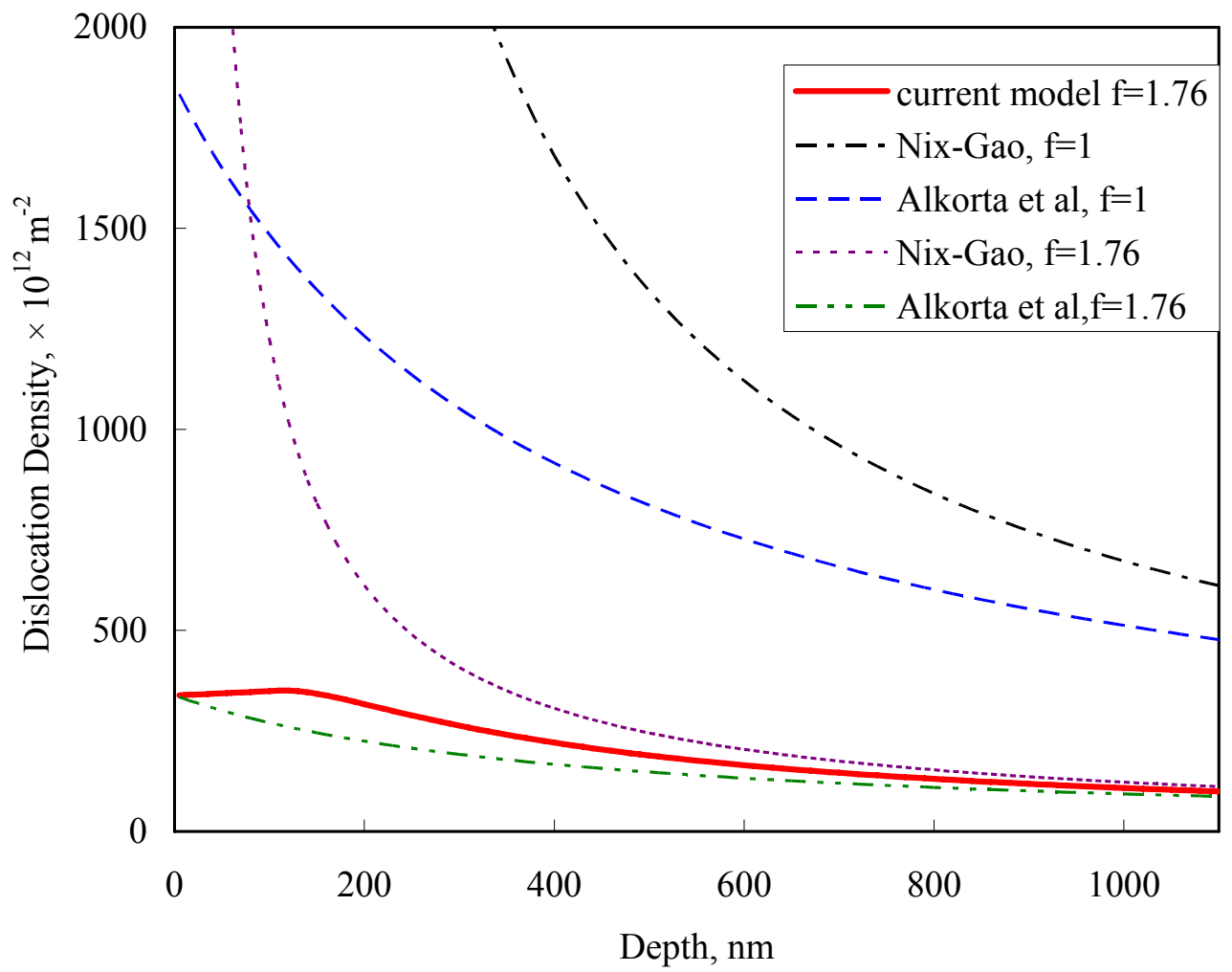

Fig. 2 Co mparison of GND densi ty predicted by vari ous models. See Ref [9, 18 ] for Nix-Gao model and Alkorta et al model, respectively. 
The cal culated GND de nsity (see Fi g. 2) a nd nanoindentation hardness (see Fi g. 6) predict a reverse ISE when the indentation depth is lower than $h_{2}$. Both experimental and finite element modelling results have proved the reverse ISE using a spherical tip $[10,28]$. W hen the indenta tion depth is larger than $h_{2}$ the current m odel shows a slower ISE than the Nix-Gao model because of the blunt tip (see Fig. 2).

The Nix-Gao $\mathrm{m}$ odel and its derivatives in cluding the cu rrent m odel calculate the average GND density underneath the indent by assum ing the GNDs are bei ng stored in a hemisphere with a specific radius. The radius of the pl astic zone in current model is assumed to be $f$ times the radius of the original Nix-Gao model. This is broadly in line with experim ents [29] and finite elem ent modelling [30,31]. The finite elem ent modelling has determ ined that valu e of $f$ ranges from 0 to 3.5, which depends on material and other parameter values such as $M$ and $C_{2}$ [30].

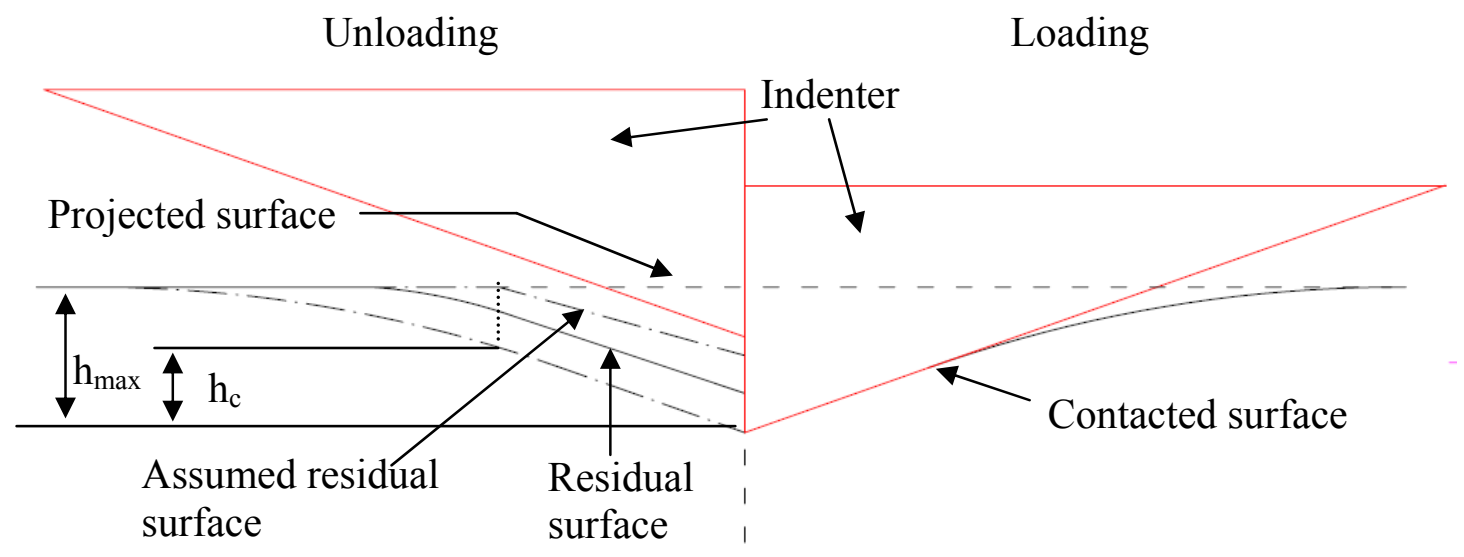

Fig. 3 Illustration of contacted area, residual area, assumed residual area and projected area during nanoindentation.

$C_{2}$ is defined as the ratio of nanoindent ation hardness to yield strength, whilst $C_{1}$ is the ratio of Vickers hardness to yield strength. This difference can be attributed to the nanoindentation and Vickers hardness being calculated using di fferent areas. As shown in Fig. 3, Vickers hardness is obtained by dividing applied force by the residual contacted area whilst nanoindenta tion hardness is cal culated using the projected area which is calculated using contact depth $h_{\mathrm{c}}$ (alternately referred to as the plastic depth, $h_{\mathrm{p}}$ ). If the residu al projected area is used to calcu late the Vickers hardness, the $\mathrm{Hv}$ value would be $8 \%$ higher than the real $\mathrm{Hv}$ value but still lower than the nanoindentation hardness. It is assumed that unloading from $h_{\max }$ to residual depth (see Fig. 3) is pure elastic [32], and then the projected area is underestimated by using 
$h_{\mathrm{c}}$, which is calculated using $h_{\max }$ by the Hertz equations [33]. In fact, the unloading is elastic and plastic [27], therefore the res idual area is larger than the assumed residual area used for nanoindentation calculation (see Fig. 3). The reverse plasticity is different for different materials so that $\mathrm{Hn} / \mathrm{Hv}$ depends on material.

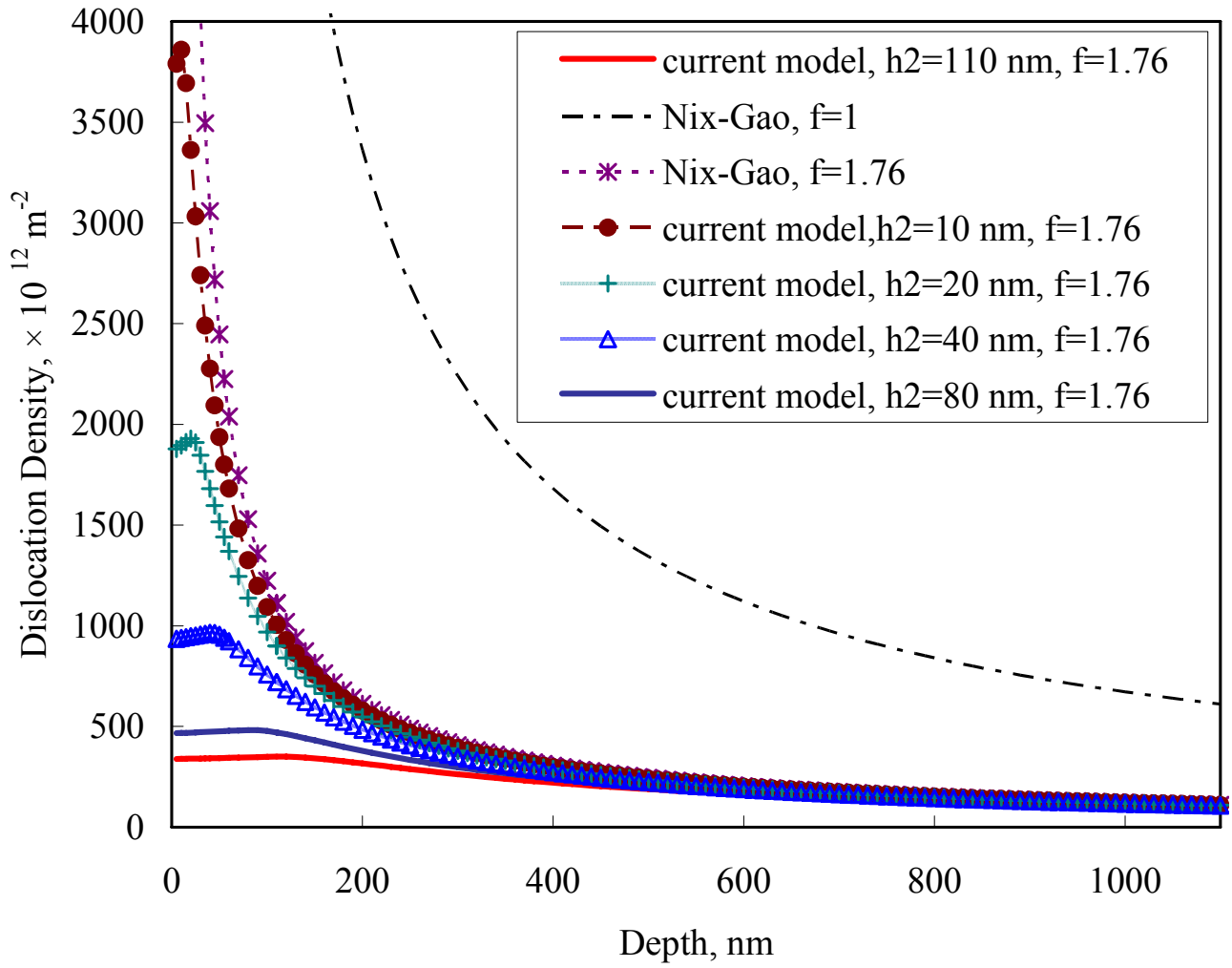

Fig. 4 Influence of rounded tip on the GND density created under different indentation depth. Se e Ref $[9,18]$ for $\mathrm{Ni}$ x-Gao m odel and Alkorta et al m odel, respectively.

Determination of $h_{2}$ is critical in current model. As shown in Fig. 4, the GND density predicted by the cur rent model is clo se to that predicted by th e Nix-Gao model with the sam e $f$ value when $h_{2}$ val ue is cl ose to zero, whi lst the GND densi ty at lower indentation depth dram atically decreases with increasing $h_{2}$ value. The blunting distance $h_{\mathrm{b}}$ of different commercial nanoindenters has been determ ined to be $6.1 \mathrm{~nm}$ to $28.8 \mathrm{~nm}[34,35,36]$. Using Eq. 13 this is equal to a range of values for $h_{2}$ of $5.7 \mathrm{~nm}$ $\sim 27 \mathrm{~nm}$. The $h_{2}$ value of a new tip produced by pr ecision polishing will be at the lower end of this range, but it will increas e due to wear of th e tip. Therefore, the $h_{2}$ value that will be determined in the curr ent work (see section 4.1) is o nly correct for our nanoindenter at the time the experiments were performed. 


\section{Materials and experimental methods}

For this work hardness nanoindentation e xperiments were carried out on ultrafine grained (UFG) Al-1050, which is co mmercial purity aluminium with composition Al$0.18 \mathrm{Fe}-0.12 \mathrm{Si}$ (in wt. \%) with further $\mathrm{m}$ inor impurities. Al-1050 was s upplied as an extruded rod of $4 \mathrm{~m}$ le ngth and $9.53 \mathrm{~mm}$ di ameter and UFG material was obtained through processing by equal channel angular pressing (ECAP) for two passes by route $B_{C}$ (further details in $[37,38]$ ). Nanoindentation experiments on UFG Al-1050 were performed using indentation depth from $100 \mathrm{~nm}$ to $800 \mathrm{~nm}$.

The nanoindenter used is m anufactured by Micro Materials Ltd, UK, equipped with a Berkovich tip. The ins trument is po sitioned on an anti-vibration base and is enclos ed in a tem perature con trolled cab inet which provides a therm ally stable environm ent. The tem perature is con trolled at $25{ }^{\circ} \mathrm{C}$ ( $\mathrm{w}$ ith expected stability $\pm 0.1{ }^{\circ} \mathrm{C}$ ) inside the cabinet, and about $24{ }^{\circ} \mathrm{C}$ outside. The indentation depths were set as $100 \mathrm{~nm}, 200 \mathrm{~nm}$, $300 \mathrm{~nm}, 400 \mathrm{~nm}$ and $800 \mathrm{~nm}$. The loadin g/unloading rate was $3 \mathrm{mN} / \mathrm{s}$. The topography of the sample after nanoindentation test was observed by an Olympus BH2 optical microscope (OM) equipped with a Prosilica dig ital CCD cam era. Micro hardness was tested on an MHT-1 model $\mathrm{m}$ icro Vickers $\mathrm{h}$ ardness tester. A force of $300 \mathrm{~g}$ was applied and holding time was 15 second.

\section{Results and Model verification}

\subsection{Determining the blunted tip radius.}

To apply the above $\mathrm{m}$ odel in the anal ysis of nanoindentation data first $h_{\mathrm{b}}$ for $\mathrm{t}$ he indenter needs to be obtained. A n eff ective way of achieving this is through calibration experiments on a calibration material with known properties. In this work, this calib ration was achieved by perform ing a series of indentations $\mathrm{w}$ ith load $\mathrm{s}$ varying from $0.5 \mathrm{mN}$ to $500 \mathrm{~m} \mathrm{~N}$ on fused silica. The elastic m odulus, hardness and Poission's ratio of this calibration material are known, and from these experiments the area values at specific depth were o btained and plotted in Fig. 5. By fitting the area and depth data using Eq. 18, $h_{\mathrm{b}}$ is determined as $117 \mathrm{~nm}$. The fit (Fig. 5) is excellent (root mean square error (RMSE) $0.090 \times 10 \quad{ }^{6} \mathrm{~nm}{ }^{2}$ ) providing confidence that the treatment of the rounded tip (section 2.1) is at least an accurate approximation. 


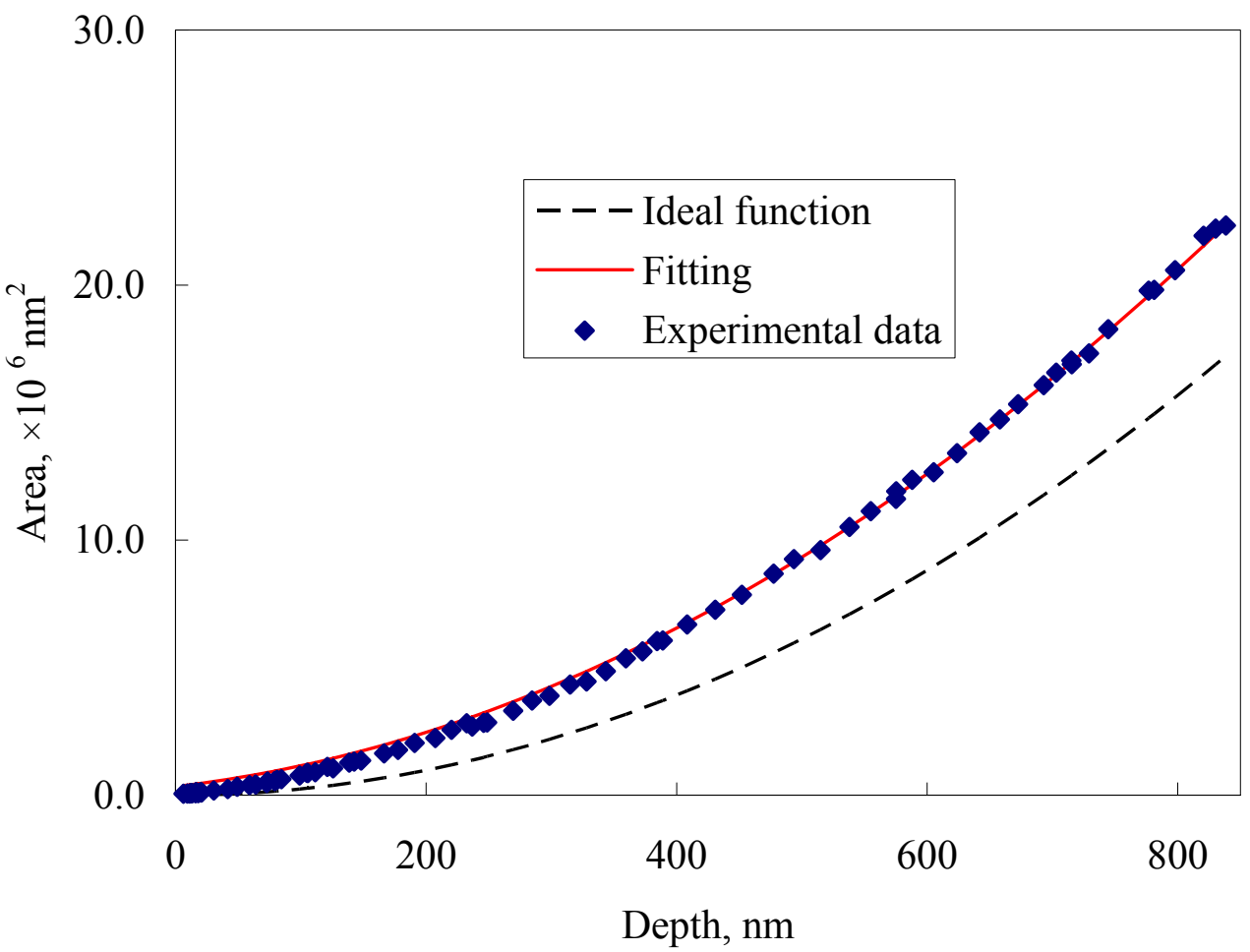

Fig. 5 Fitting of $h_{\mathrm{b}}$. The blue cubes are the area function measured by experiments; the dash line is ideal function for the sharp tip; the red line is fitting curve using Eq. 18.

\subsection{Predicting nanoindentation hardness of UFG Al-1050.}

To provide a critical ass essment of the model we decided to perfor $m$ nanoindentation tests on a $\mathrm{m}$ aterial $\mathrm{f}$ or $\mathrm{w}$ hich the ISE has $\mathrm{n}$ ot been tes ted prev iously, $\mathrm{w}$ ith a microstructure that contains substantial strengthening contributions besides the GNDs, whilst the parameters in the model are known to a good accuracy. UFG Al-1050 was selected. We will first show that all parameters are (essentially) known.

It was shown before that the $C_{1}$ value for worked Al-1050 ranges from 3.05 to 3.28 [37], we wi 11 here t ake $C_{1}$ as the average over that rang e, ie. $C_{1}=3.16$. W ork on a range of alloys [27] has shown that nanoi ndentation hardness is $10-30 \%$ higher than the Vickers hardness, in the cu rrent work we will take $C_{1} / C_{2}$ of Al-1050 as equal to that of $\mathrm{Cu}(0.8$ [27]). The Vickers hardness of the present UFG Al-1050 was measured to be $44 \mathrm{Hv}$. The $\sigma_{0}$ of Al-1050 is taken as $28 \mathrm{MPa}$ [39], which is the yield strength of Al-1050 in fully annea led condition. The value of $\Delta \sigma_{\mathrm{gb}}$ is calculated using the approach outlined in [24], whic h provides $\Delta \sigma_{\mathrm{gb}}=5 \mathrm{MPa}$ (see also [37]). $M$ and $G$ are taken as 2.6 [40] and $26 \mathrm{GPa}$ [41], respectively. This leav es just $f$ to be fitted. We 
would expect $f$ is close to the value of 1.9 det ermined for single crystalline copper, annealed polycrystalline copper, UFG copper and polycrystalline iron [22].

The predicted nanoinde ntation hardness with a fitted value $f=1.76$, is presented in Fig. 6. A very good correspondence is found with RMSE of $0.011 \mathrm{GPa}$. The m easured and predicted nanoindentation values are plotted in Fig. 7.

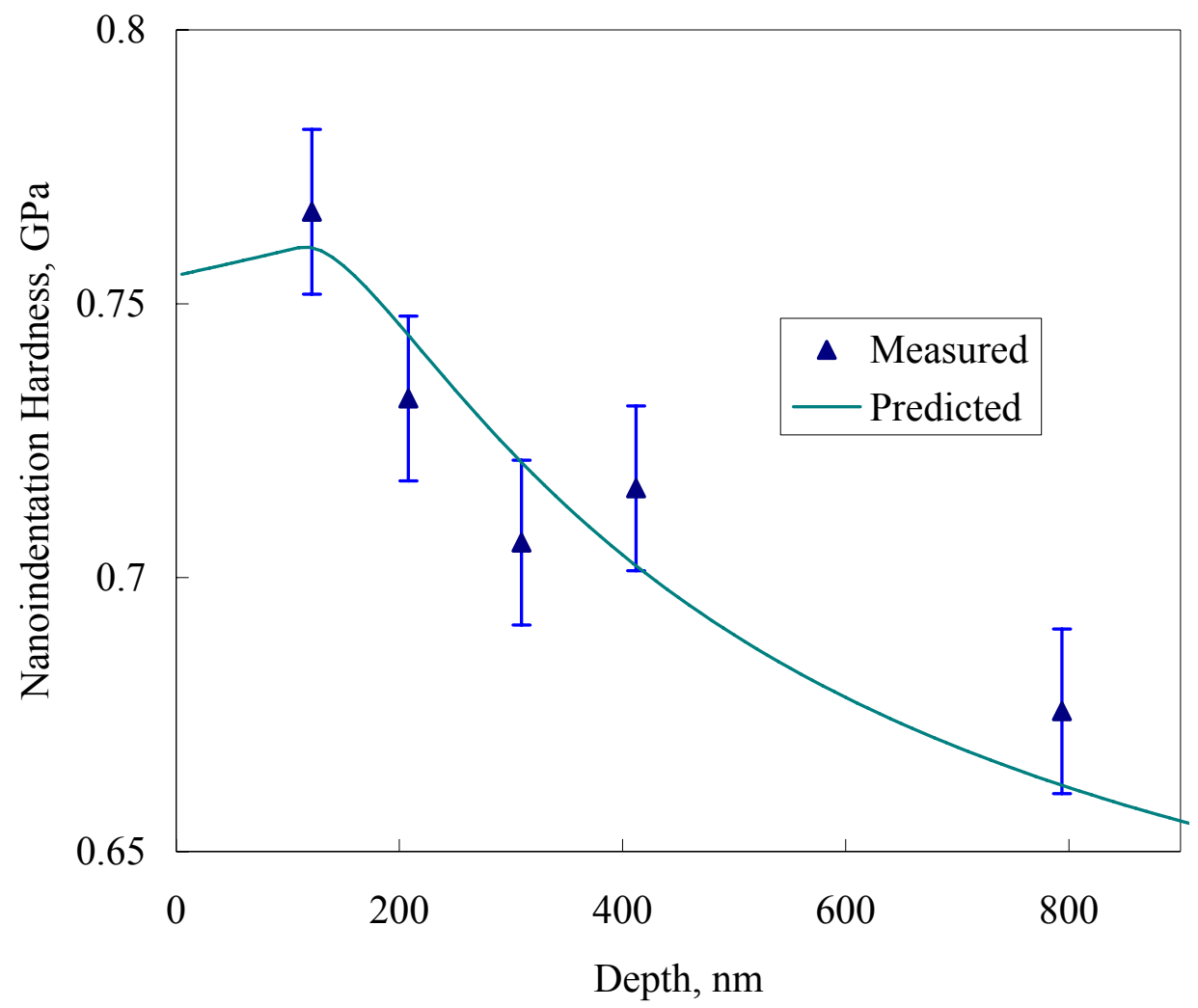

Fig. 6 Measured and predicted nanoindenta tion value against the ind entation depth. The error bars represent standard deviations.

Fig. 6 show $\mathrm{s}$ the $\mathrm{m}$ easured and predicted nanoindentation hardness as a function of the indentation depth. The predicted values successfully captured the measured trend. The nanoindentation hardness decreases with increasing indentation depth but the rate of decrease is slow when the depth is larger than $400 \mathrm{~nm}$.

The present data shows a highe $r$ scatter than experimental data on polycrystalline and single crystal $\mathrm{m}$ aterials reported in a range of papers. This is due to the $\mathrm{m}$ ore inhomogeneous nature of the present UF G Al-1050 (see Ref [37]). This, however, does not impinge on the $\mathrm{m}$ ain conclusion here, i.e. the good predictions of th $\mathrm{e}$ nanoindentation hardness. 


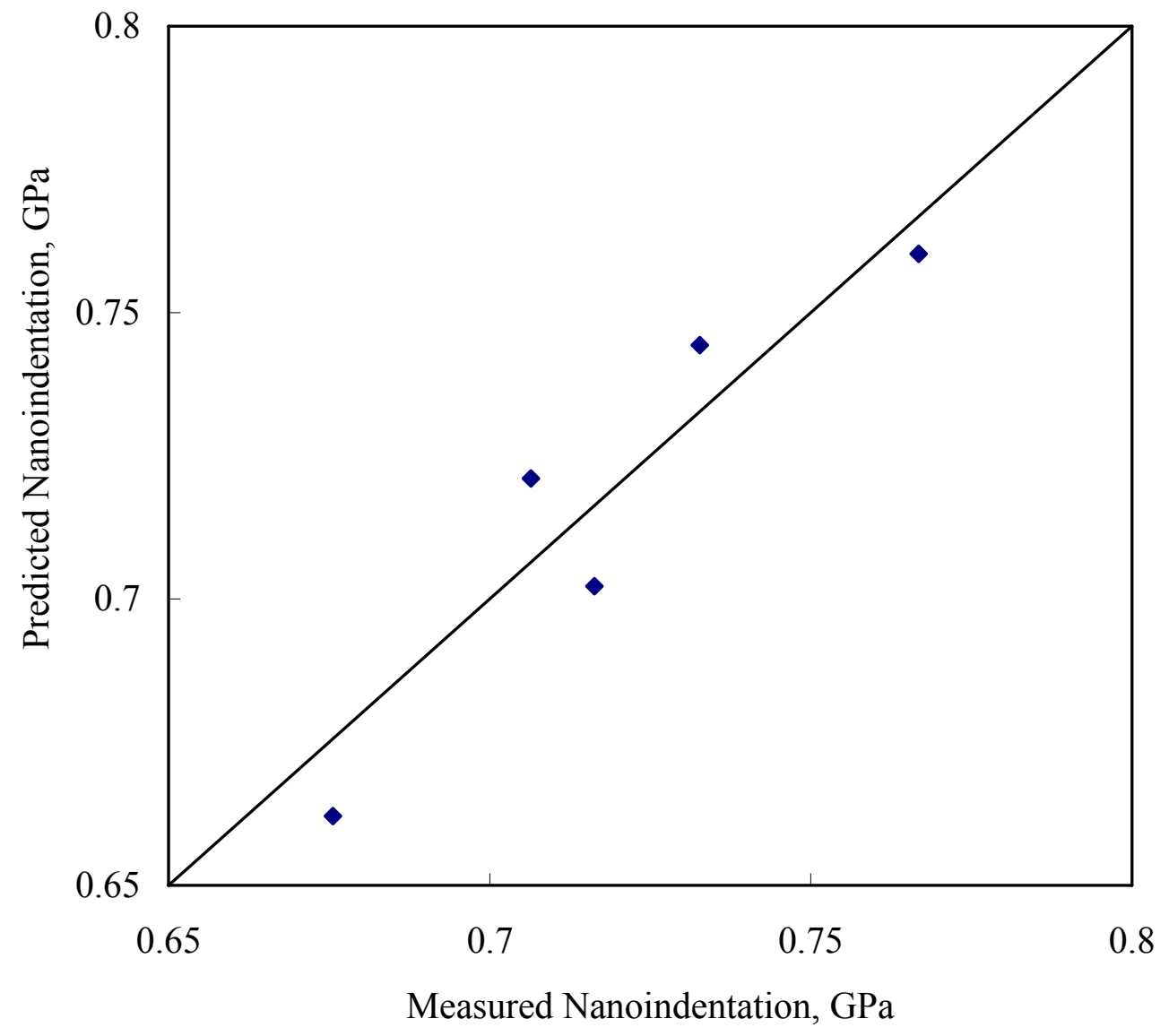

Fig. 7 Measured and predicted nanoi ndentation value of UFG Al-1050. The indentation depth ranges from $100 \mathrm{~nm}$ to $800 \mathrm{~nm}$.

\subsection{Predicting dislocation densities}

In a further test for the model we will predict dislocation densities and compare those against measured values by De mir et al [42] for (111) copper single crystals. In the latter work dislocation densities w ere obtai ned from analysis of cross sections of deformed material under a rounded tip with diameter of $1 \mu \mathrm{m}$ using 3-D EBSD. (Note that in Fig 2 in Ref [42] depth are mislabelled). The average values of measured GND densities at different indentat ion depths have been replotted in Fig. 8, and various model predictions are included in the figure. The GND dens ity shows increases with the indentation depth, and this is captured well by the present model if the value of $f$ is set to 1.4. (The slightly larger deviation between predicted and measured value for the data point at the larger indentation $d$ epth could be because the radius value (reported 
to be $R=1 \mu \mathrm{m}$ [42]) of the tip having increas ed due to wear. The cu rrent model would give good predictions for all the four GND densities if $R=1.3 \mu \mathrm{m}$.)

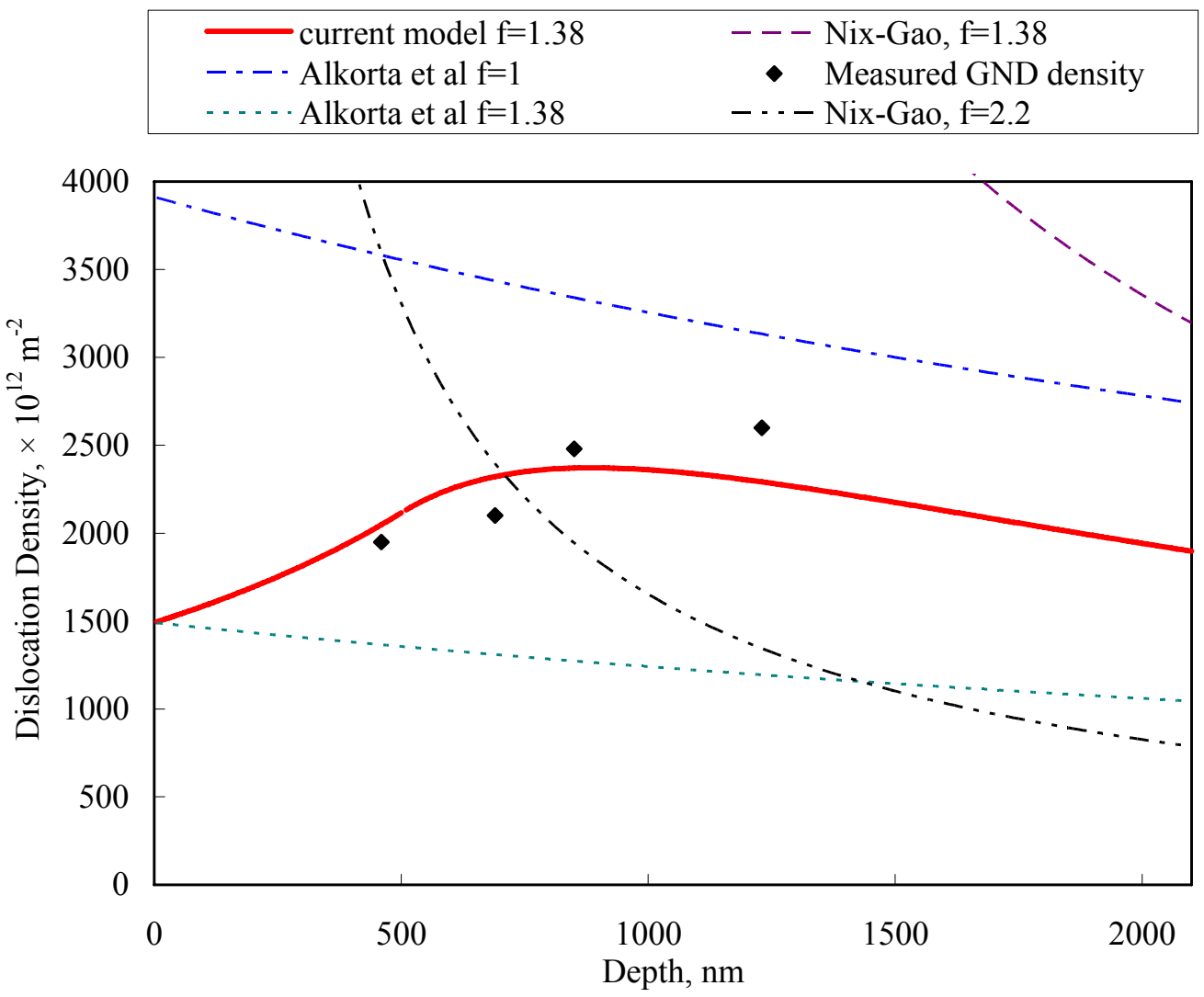

Fig. 8 Evolution of $m$ easured and pred icted GND density of (111) copper single crystal $w$ ith the indenta tion depth. The $m$ easured data are $t$ aken fro $m[42]$. A $60^{\circ}$ conical tip with a rounded tip in diameter of $1 \mu \mathrm{m}$ was used.

Fig. 8 shows that the models for a sharp indenter (the Nix-Gao model [9], the Abu AlRub model [15] and the Durst et al model (the Nix-Gao model with an adjustable $f$ $[22,23])$, predict dislocation densities that are very different from the ones $m$ easured underneath the spherical inde nter. The Huang et al $\mathrm{m}$ odel [21] assumes the GND density is constant when the indentation d epth is less than a spec ific value $h_{\text {nano }}^{*}$. If taking the height of the tip in spherical cap part (500 nm ) as the $h_{\text {nano }}^{*}$ value, the GND densities predicted by Huang et al model [21] are 5-12 times larger than experimental results (not shown i n Fi g. 8 because they are out of range). The GND densi ty predicted by the original Alkorta et al m odel [18], i.e. with $f=1$, is much larger than the experimental results. Adjusting $f$ will bring values broadl $\mathrm{y}$ within range but this model will fail to predict that the GND density increases with the indentation depth at 
lower depth. The reason for this is tw o fold. Firstly, the Alkorta et al model assume the contact area and indentation depth follo ws Eq. 19, which causes the GND densi ty predicted to be $\mathrm{m}$ uch low er than that predicted by current $\mathrm{m}$ odel (except for $h$ approaching 0 where the two m odels converge, but that is not a realistic indentation). Secondly, Alkorta et al [ 18] calculate the total lengt $h$ of the GND based on the approximation:

$$
\lambda=\int_{0}^{h_{\mathrm{f}}} \frac{2 \pi}{b} r(h) \mathrm{d} h=\frac{2 \pi \tan \phi}{b} \int_{0}^{h_{\mathrm{f}}} \sqrt{h^{2}+\delta h} \mathrm{~d} h, \delta=\frac{2 R}{(\tan \phi)^{2}}
$$

i.e,

$$
r(h)=\tan \phi \sqrt{h^{2}+\frac{2 R}{\tan ^{2} \phi} h}
$$

Eq. 25 is correct only when the depth is large, i.e, $\quad r(h)>r_{0}$ (see Fig. 1). However, without justification Alkorta et al extend Eq. 25 to apply at lower indentation depth, i.e. $r(h)<r_{0}$. The second assumption leads to the Alkorta et al $\mathrm{m}$ odel predicting an incorrect trend at lo wer indentation de pth. As a result of these inaccu rate approximations the Alk orta et al model is only accurate for $h=0$ and for the limit for high $h$, typically $h>>500 \mu \mathrm{m}$, leaving the m odel to be ina ccurate in the range tha $t$ is relevant.

From this section we conclude that where other models fail, our m odel predicts the correct magnitude and trend in dislocation densities under a spherical indenter.

\subsection{ISE of several FCC materials}

As a final test for ou $\mathrm{r}$ m odel we will compare its pred ictions aga inst published nanoindentation ISE data for a range of materials.

\section{$\underline{\text { ISE in Ir- } 0.3 \mathrm{wt} \% \mathrm{~W}}$}

Swadener et al. [10] $\mathrm{m}$ easured nanoinde ntation hardness and $\mathrm{m}$ icrohardness of annealed Ir- $0.3 \mathrm{wt} \% \mathrm{~W}$ (with $60 \mathrm{ppm}$ Th by weight) at the indentation depth from 150 $\mathrm{nm}$ to $50000 \mathrm{~nm}$. The nanoindentation hardness was measured using the Oliver-Pharr method [32], i.e. through determining the contact depth $\left(h_{\mathrm{c}}\right)$ by Hertz elastic equations during loading and unloa ding, then converting $h_{\mathrm{c}}$ to projected contact area using an area function. In Fig. 9 the $\mathrm{m}$ easured data [10] are compared with model predictions. In the current model, $G$ and $b$ were taken as $217 \mathrm{GPa}[10,21]$ and $0.271 \mathrm{~nm}[10,21]$. The yield s trength of the Ir- $0.3 \mathrm{wt} \% \mathrm{~W}$ is $338 \mathrm{MPa}$ (determ ined from data in $[10,21]$ ) 
and the value of $\sigma_{0}+\sigma_{\mathrm{GB}}$ is estimated as $0.8 \sigma_{\mathrm{y}}$, which is reasonable for an annealed alloy. The other param eters, including $C_{1}, C_{2}$ and $M$, were taken as the sam e values with Al-1050. The radius of rounded tip, $\quad R$, plastic zo ne factor, $f$, and Vickers hardness $\mathrm{H} \mathrm{v}$ were determ ined as $288 \mathrm{~nm}, 1.94$ and $3.0 \mathrm{GPa}$ by fitting to the experimental nanoindentation data. As shown in Fig. 9 and Fig. 10, the predicted nanoindentation hardness by the current $\mathrm{m}$ odel fits the experimental results to a very high accuracy and within the standard deviation of the experimental data. Furthermore, the value s for the 3 par ameters as determ ined by fitting are reasonable. Firstly, the value of $R$ (determined to be $288 \mathrm{~nm}$, which corresponds to a blunting distance of 18 $\mathrm{nm}$ ) is between the radius of a new Ber kovich tip (about $50 \mathrm{~nm}$ ) and the value at which a worn tip will generally be reported as a defective tip ( $\sim 500 \mathrm{~nm} \quad$ [14]. Secondly, the $f$ value of $\mathrm{Ir}-0.3 \mathrm{wt} \% \mathrm{~W}$ determined by the present model (1.94) is closed to the $f$ value of Al-1050 (1.76). Furthermore, Durst et al [23] determined $f$ for coarsegrained copper, UFG copper, coarse-grained aluminium and UFG alum inium as 1.9, which is also close to current determination. Finally, the Hv value determined by the present model $(3.0 \mathrm{GPa})$ is close to the measured microhardness $(2.6 \mathrm{GPa})$ determined at large depth by Swadener et al [10].

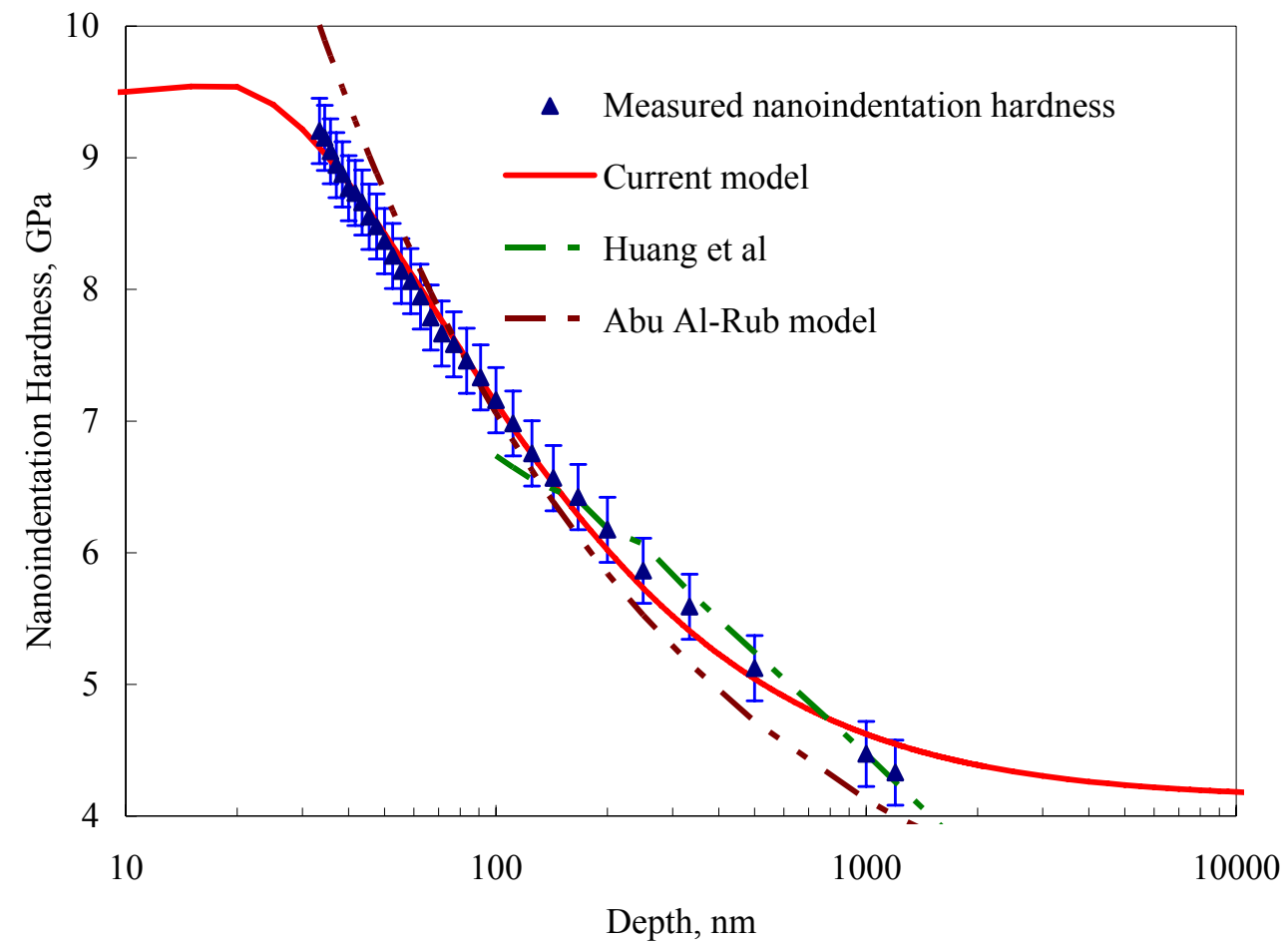

Fig. 9 Comparison of the prediction of th e nanoindentation hardness of annealed Ir$0.3 \mathrm{wt} \% \mathrm{~W}$ by Huang et al model [21], Abu Al-Rub model [15] and current model. The nanoindentation hardness data are taken from [10]. 
Fig. 9 also shows nanoindentation hardness of Ir- $0.3 \mathrm{wt} \% \mathrm{~W}$ predicted by the Huang et al [21] m odel and the Abu Al-Rub m odel [1 5]. In their model, Huang et al [21] assume the GND density reaches a $\mathrm{m}$ aximum value, which is called $\mathrm{m}$ aximum allowable GND density when the indentation depth $h$ is less than a specific value $h_{\text {nano }}^{*}$. The value of GND density is $\mathrm{r}$ elated to $h_{\text {nano }}^{*}$, the value of $\mathrm{w}$ hich is deter mined by fitting. As seen in Fig. 9, predictions using the Huang et al [21] model broadly capture the trend, but the increasing deviation be tween prediction and $\mathrm{m}$ easured values for decreasing depth suggests that this model will fail for depths less than $100 \mathrm{~nm}$. Huang et al [21] did not provide predictions for the nanoindentation with depths less than 100 $\mathrm{nm}$. The Abu Al-Rub model [15] also fails to accurately capture the trend producing an overestim ate at indentation depths under $100 \mathrm{~nm}$ but an underestim ate at the indentation depths larger than $100 \mathrm{~nm}$. A summary of the accuracies achieved by the various models is presented in Table 1.

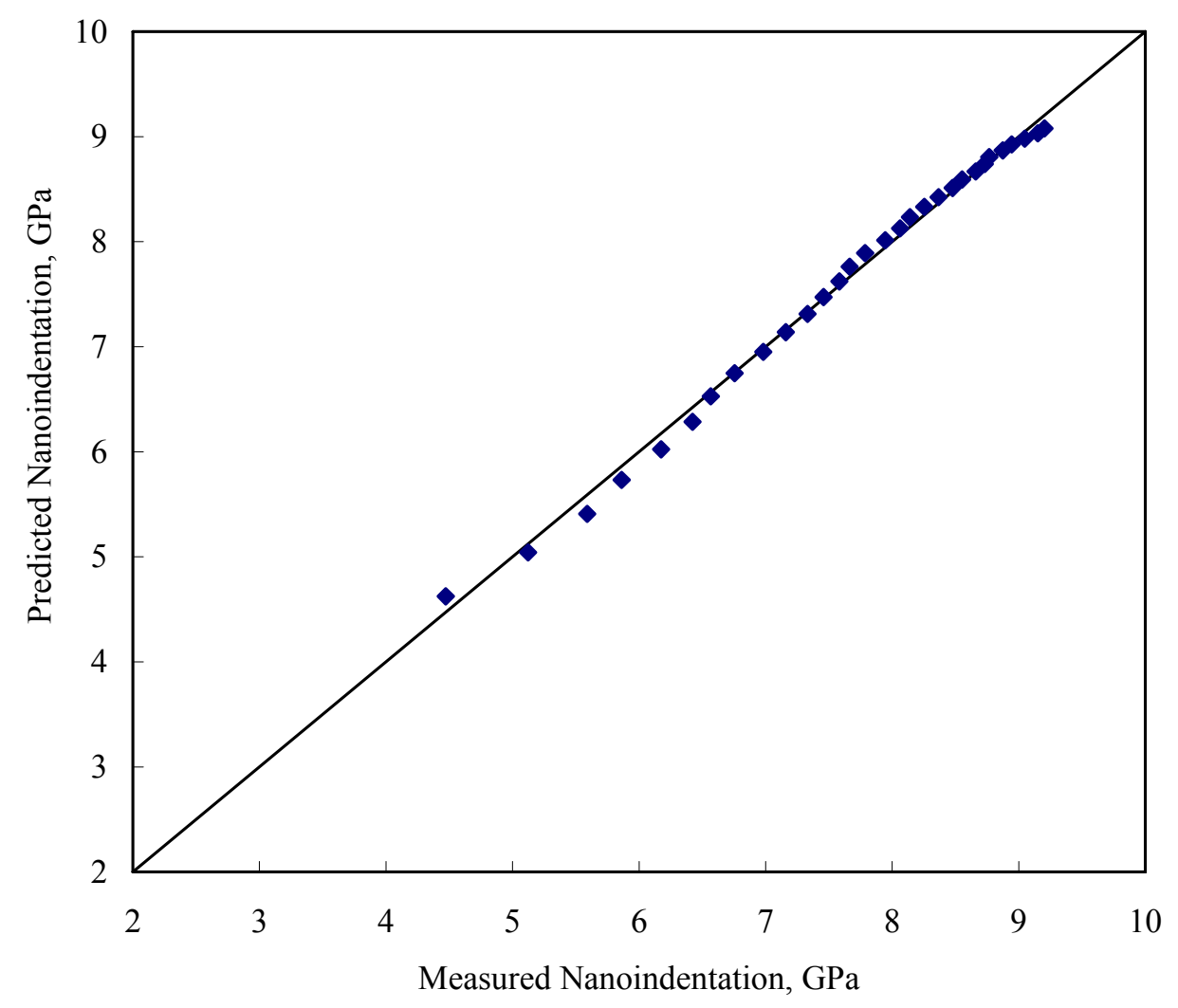

Fig. 10 The $\mathrm{m}$ easured nanoindentation ha rdness of ann ealed $\mathrm{Ir}-0.3 \mathrm{wt} \% \mathrm{~W}$ and predicted nanoindentation by th e current $\mathrm{m}$ odel. The experim ental data were taken from [10]. 
It is worth noting that in Ref [10] microhardness was measured using a microhardness tester equipped with a Berkovich tip for lower depths and a Rockwell hardness tester for larger depths. The indent area was $\mathrm{m}$ easured by a video $\mathrm{m}$ icroscope system, i.e. the measured area is res idual area, which is different with the pr ojected contact area determined in nanoindentation hardness. As a result, the $\mathrm{m}$ icrohardness measured in Ref [10] can not be si mply considered as the nanoindentation hardness with a higher indentation depth because the ratio of hardness to yield strength $(C)$ is different in nanoindentation hardness and microhardness.

\section{$\underline{\text { ISE in single crystal } \mathrm{MgO}}$}

Feng and Nix [12] $\mathrm{m}$ easured nanoindentat ion hardness of single crystal $\mathrm{MgO}$. The experimental data are replotted in Fi g. 11. In the current $\mathrm{m}$ odel, a fixed $f$ value was used. The value of $b, G$ and intrinsic stress of $\mathrm{MgO}$ were taken from [12, 21] as 0.298 $\mathrm{nm}, 126 \mathrm{GPa}$ and $0.18 \mathrm{GPa}$ The rem aining parameters were taken as the sam e values used for Al-1050. The prediction curve is shown in Fig. 11. The values of $f, H \mathrm{v}$ and $R$ were determined as 1.13, $6.9 \mathrm{GPa}$ and $764 \mathrm{~nm}$ by fitting. The exponential relationship between $f$ and $h$ determined by Feng and $\mathrm{Ni}$ x [12] provides an average $f$ value for $0<h<500 \mathrm{~nm}$ of 1.11 , which is close to current $f$ value. The current $H \mathrm{v}$ value ( $6.9 \mathrm{GPa}$ ) is $25 \%$ lower than the nanoindentation har dness with large indentation depth $(9.19$ $\mathrm{GPa}$, see Fig. 11), which is reasonable because the $\mathrm{n}$ anoindentation hardness is 10$30 \%$ higher than Vickers hardness using th e sam e load [27]. The radius of the blunting tip was determ ined as $764 \mathrm{~nm}$ in current model, i.e. the blunting distance $h_{\mathrm{b}}$ is $47 \mathrm{~nm}$ (see Eq. 12 and Eq. 13), which has been proved by the experimental data in Fig. 11 whe re the nanoindentation hardness st arts to decreas e when the indentation depth is lower than $50 \mathrm{~nm}$. Thus the va lues of all three fitted param eters, $f, H \mathrm{v}$ and $R$, are very close to values that can be experimentally determ ined through direct experiments.

Predictions by Huang et al model [21] and Abu Al-Rub model [15] are also shown in Fig. 11. For both m odels, predictions are close to the exp erimental data, but the fit is not perfect, especially when it is considered that 3 or 4 para meters are fitted, in many cases with little justification provided for the values obtained. In contrast, the current model fits the experimental data near perfectly, whilst, as shown above, the values of the 3 fitted parameters can be jus tified to within a few percent. RMSE of the fits are presented in Table 1. At low indentati on depth, the current $m$ odel predicts the 
indentation hardness decreases with decreasing depth because of the tip radius effect. For the whole range of the experim ental indentation depth, the hardness predicted by the current model fits the $\mathrm{m}$ easured hardne ss to a very hig h accuracy (see Fig. 12), with root mean square error of $0.068 \mathrm{GPa}(2.5 \%$ of the range of values).

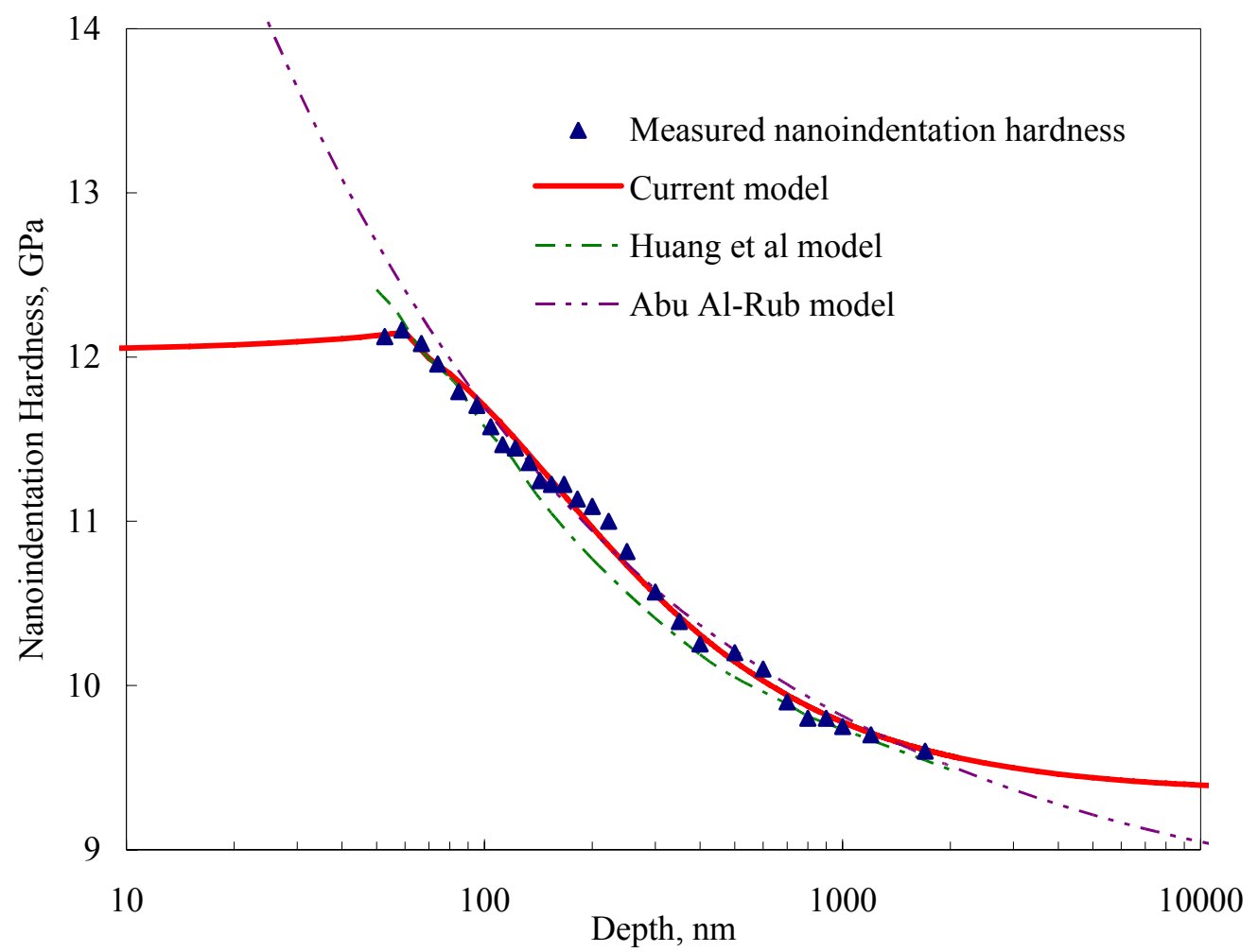

Fig. 11 Comparison of the prediction of the nanoindentation hardness of single crystal MgO by Huang et al m odel [21], Abu Al-Rub model [15] and the current m odel. The nanoindentation hardness data are taken from [12].

\section{$\underline{\text { Summary of ISE data }}$}

We further $\mathrm{m}$ ade $\mathrm{m}$ odel predictions for si ngle crystal $\mathrm{Cu}$ and work hardened $\mathrm{Cu}$ (experimental data are from Ref [43]), and the RMSE values are reported in Table 1. The predictions are good over the entire range ( $80 \mathrm{~nm}$ to $2000 \mathrm{~nm}$ ). Nix and Gao [9] excluded the nanoindentation hardness with indentati on depth less than $150 \mathrm{~nm}$ because the Nix-Gao model substantially deviates from the experimental data at lower depth. (We did not attempt to fit the experim ental data of single crystal Ag in Ref [6], replotted by Nix and Gao [9], because th e residual pro jected area was used to calculate the nanoindentation hardness in original paper.) 


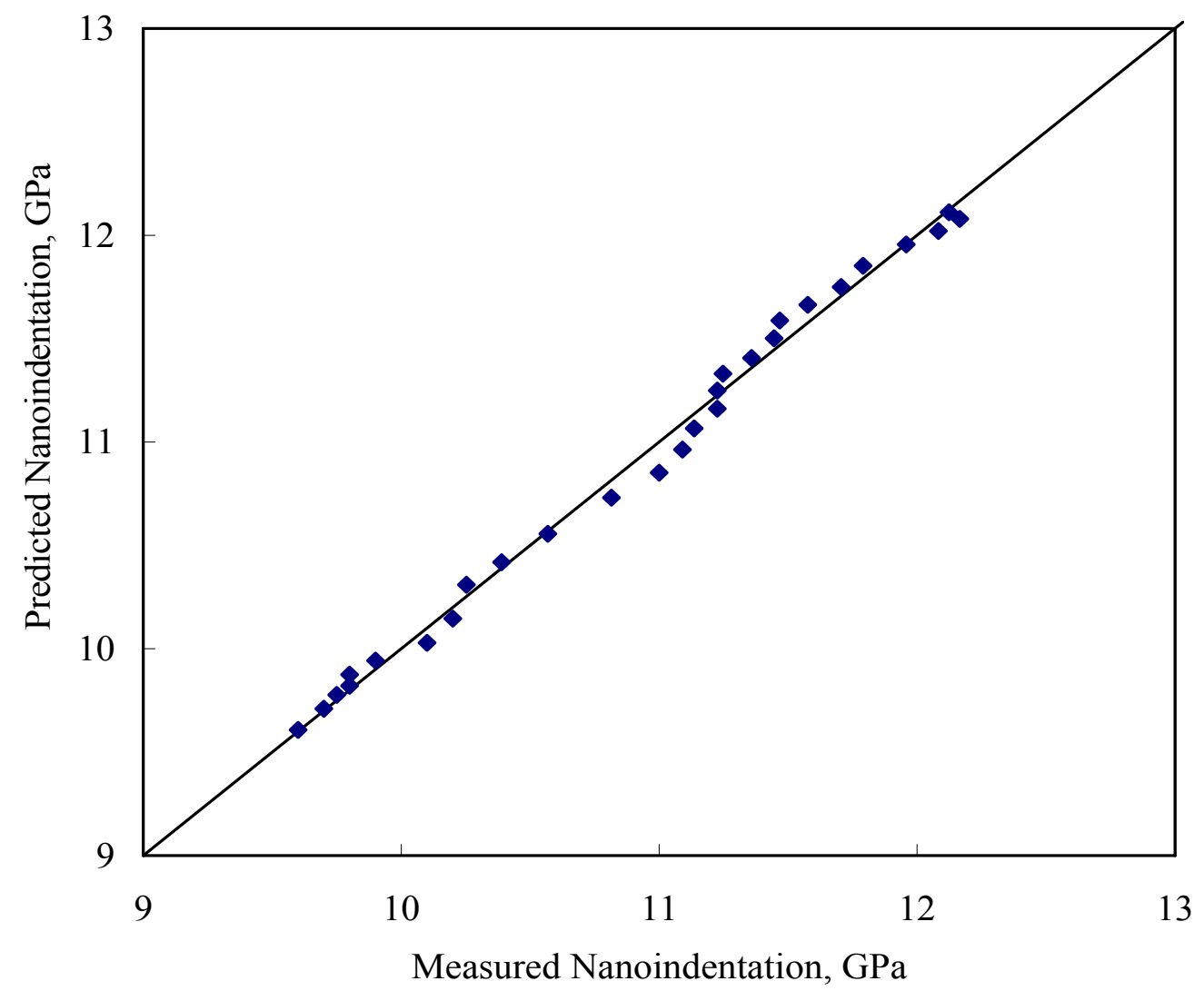

Fig. 12 The m easured nanoindentation har dness of single crysta $1 \mathrm{MgO}$ and predicte $\mathrm{d}$ nanoindentation by the current model. The experimental data were taken from [12].

\section{Discussion}

In the above we have shown that a com putationally friendly analytical model for the ISE can be derived which in corporates a blunted nanoinde nter tip and an effectiv e plastic zone size that scales with the indent size. It is show $n$ that the indenter size can be determ ined through calibration expe riments. The model is tested again st nanoindentation data and disloc ation density $\mathrm{d}$ ata, and is shown to be substantially more accurate th an ex isting $\mathrm{m}$ odels. Model param eters can in $\mathrm{m}$ any cases $\mathrm{b}$ e determined from independent experim ents, and where fitting is neces sary they a re within ranges that can be jus tified. We thus conclude that the present model is very useful in analysis nanoindentation ISE data, and can solve som e of the issues regarding the ISE that have hith erto remained unexplain ed. Specifically, the m odel demonstrates that where several existi ng m odels showed (1 argely unexplained) deviations with measured data at small indentation depths (typically $30-150 \mathrm{~nm}$ ), the 
present model does provide good fits in that range. This shows quantitatively that deviations from earlier models can be (largely) due to the tip rounding artefact.

It is $f$ urther noted that if we consider th at the effects for even sm aller indentations, which involve a pop-in event occurring during the transition from elastic to plastic loading, are reasonably well understood (see Durst et al [23]), it thus appears that the entire ISE o ver all indentation sizes can be fully explained on the basis of the strain gradient plasticity and GNDs.

Table 1 RMSE of nanoindentation hardness predictions by three models.

\begin{tabular}{ccccc}
\hline & \multicolumn{3}{c}{ RMSE of prediction } & \multirow{2}{*}{$\begin{array}{c}\text { Source of exp } \\
\text { data }\end{array}$} \\
\cline { 2 - 4 } & $\begin{array}{c}\text { Huang et al } \\
\text { model [21] }\end{array}$ & $\begin{array}{c}\text { Abu Al-Rub } \\
\text { model [15] }\end{array}$ & $\begin{array}{c}\text { Present } \\
\text { model }\end{array}$ & \\
\hline Ir-0.3wt\%W 201 & $\mathrm{MPa}^{\text {a) }}$ & $412 \mathrm{MPa}$ & $92 \mathrm{MPa}$ & {$[10]$} \\
MgO & $141 \mathrm{MPa}$ & $137 \mathrm{MPa}$ & $68 \mathrm{MPa}$ & {$[12]$} \\
Single crystal Cu & - & - & $45 \mathrm{MPa}$ & {$[43]$} \\
Cold worked Cu & - & - & $22 \mathrm{MPa}$ & {$[43]$} \\
Al-1050 & - & - & $11 \mathrm{MPa}$ & Present work \\
Fitted parameters & 34 & & $1^{\text {b) }}, 2^{\text {c) }}, 3^{\text {d) }}$ & \\
\hline
\end{tabular}

a) Model only predicts $100-1000 \mathrm{~nm}$ range. RMSE error is for that limited range.

b) Only the value of $f$ is fitted for Al-1050 and single crystal $\mathrm{Cu}$.

c) $f$ and $R$ are fitted for work hardened $\mathrm{Cu}$.

d) $f, H \mathrm{v}$ and $R$ are fitted for $\mathrm{Ir}-0.3 \mathrm{wt} \% \mathrm{~W}$ and $\mathrm{MgO}$.

The current m odel uses a 1 inear superpos ition rel ation of GNDs and SSDs (see Eq. 24), which was used by $m$ any researchers $[8,9,16,21,42,44,45]$ and provided fairly good predictions for single crystal $\mathrm{m}$ aterials and annealed $\mathrm{m}$ etals. However, it has been shown [43] that at lower indentat ion depths cold worked $\mathrm{Cu}$ has lower nanoindentation hardness than single $\mathrm{cr} \quad$ ystal $\mathrm{Cu}$ (using area corrected by $\mathrm{SE} \quad \mathrm{M}$ measurements [43]). Thi s can not be cap tured through a simple linear superposition relation of GNDs and SSDs. Henc e, we bel ieve that a further refi nement of m odels will be needed to acco unt for the interact ion of pre-stored di slocations, GNDs a nd SSDs generated during nanoinde ntation, especially when high densities of SSDs are present due to prior working. This is b ecause the large am ount of newly generated dislocations (GNDs and SSDs) and pre-stored dislocations increase the possibility of annihilation of dislocations on the sam e slip plane with different signs. Further, significant am ount of GNDs and SSDs genera ted during nanoindentation of cold worked metals, especially for severely plastically deformed metals, will form new cell 
walls/grain boundaries or are absorbed by existing cell walls/grain boundaries [38]. As a result, the tota 1 disloc ation d ensity decreases and grains are refined. These effects will cause dev iations from a lin ear superposition relation of GND and SSD densities.

\section{Conclusions}

A m odel e mploying the concept of geom etrically necessary dislocations was established to interp ret the indentation size effect for an indenter with a tip worn to a rounded shape. Conclusions are drawn as follows:

- The blunting distance $h_{\mathrm{b}}$ (and tip ra dius) can be determined by fitting the area function.

- The ratio of nanoindentation ha rdness to the yield strength $\left(C_{2}\right)$ is larger than that of the Vickers (micro) hardness to the yield strength (typically, $C_{1}=3.16$ ).

- The current m odel successfully predicts the GND densi ty increases with the increasing indentation depth at lower depth under the rounded conical tip.

- The current model for indenter with worn tip a ccurately fits the exper imental ISE data of a range of ma terials in a range where other models have proved to be inaccurate.

\section{Appendix}

Eq. 17 and Eq. 18 are valid when $\quad h>h_{2}$. If $h<h_{2}$, the indent shap e w ill b e pu re spherical and the total length of GNDs are as follows:

$$
\begin{aligned}
\lambda(h) & =\int_{0}^{r} 2 \pi r \frac{d r}{S}=\int_{0}^{r} 2 \pi r \frac{\tan \theta}{b} d r=\int_{0}^{\theta} \frac{2 \pi R^{2} \sin ^{2} \theta}{b} d \theta=\frac{\pi R^{2}}{b}(\theta-\sin \theta \cos \theta) \\
& =\frac{\pi}{b}\left[R^{2} \arccos (1-h / R)-(R-h) \sqrt{2 R h-h^{2}}\right]
\end{aligned}
$$

where, $\theta=\operatorname{arcos}(1-h / R)$ and $R=1883.5 \mathrm{~nm}$ (see Eq. 12). Substitu ting Eq. 27 in $\rho=\frac{\lambda(h)}{V}$, provides the GND density as:

$\rho_{\mathrm{GND}}=\frac{3(\theta-\sin \theta \cos \theta)}{2 b f^{3} R \sin ^{3} \theta}=\frac{3\left[R^{2} \arccos (1-h / R)-(R-h) \sqrt{2 R h-h^{2}}\right]}{2 b f^{3}\left(2 R h-h^{2}\right) \sqrt{2 R h-h^{2}}}$ 
Eq. 28)

In this case the projected contact area is given by

$$
A_{c}=\pi a_{c}^{2}=\pi R^{2} \sin ^{2} \theta=2 \pi R h-\pi h^{2} \quad \text { Eq. 29) }
$$

\section{Acknowledgements}

This work was funded in part by the Engi neering Physics Scien ce Research Council under Grant No. EP/D00313X/1. Author XGQ thanks ORSAS a nd School of Engineering Sciences of University of Southam pton for a dditional studentship funding. Dr. Dan Sun and Dr. Jurgita Zekony te (University of Southam pton) are gratefully acknowledged for assistance on nanoindentation.

\section{References}

[1] Aifantis E. J Eng Mater Techn 1984;106:326

[2] Fleck NA, Hutchinson JW. J Mech Phys Solids 1993;41:1825

[3] Aifantis E. Int J Plasticity 1987;3:211

[4] Gao H, Huang Y, Nix WD, Hutchinson JW. J Mech Phys Solids 1999;47:1239

[5] Stelmashenko NA, Walls MG, Brown LM, Milman YV. Acta Metall 1993;41:2855

[6] Ma Q, Clarke DR. J Mater Res 1995;10:853

[7] Ashby MF. Phil Mag 1970;21:399

[8] Fleck NA, Muller GM, Ashby MF, Hutchinson JW. Acta Metall 1994;42:475

[9] Nix WD, Gao H. J Mech Phys Solids 1998;46:411

[10] Swadener JG, George EP, Pharr GM. J Mech Phys Solids 2002;50:681

[11] Lim YY, Chaudhri MM. Philos Mag A 1999;79:2979

[12] Feng G, Nix WD. Scripta Mater 2004;51:599

[13] Elmustafa AA, Stone DS. J Mech Phys Solids 2003;51:357

[14] Chicot D. Mater Sci Eng A 2009; 499: 454

[15] Abu Al-Rub RK, Mech Mater 2007;39:787

[16] Huang Y, Xue Z, Gao H, Nix WD, Xia ZC. J Mater Res 2000;15:1786

[17] Huang Y, Qu S, Hwang KC, Li M, Gao H. Int J Plast 2004;20:753

[18] Alkorta J, Martınez-Esnaola JM, Sevillano JG. Acta Mater 2006;54:3445

[19] Qu S, Huang Y, Nix WD, Jiang H, Zhang F, Hwang KC. J Mater Res 2004; $19: 3423$

[20] Xue Z, Huang Y, Hwang KC, Li M. ASME J Eng Mater Technol 2002;124:371

[21] Huang Y, Zhang F, Hwang KC, Nix WD, Pharr GM, Feng G. J Mech Phys

Solids 2006;54:1668

[22] Durst K, Backes B, Goken M. Scripta Mater 2005;52:1093

[23] Durst K, Backes B, Franke O, Goken M. Acta Mater 2006;54:2547

[24] Starink MJ, Wang SC. Acta Mater 2003;51:5131

[25] Zhu Z, Starink MJ. Mater Sci Eng A 2008;489:138

[26] Starink MJ, Deschamps A, Wang SC. Scripta Mater 2008;58:377

[27] Qian L, Li M, Zhou Z, Yang H, Shi H. Surf Coat Techol 2005;195:264

[28] Qu S, Huang Y, Pharr GM, Hwang KC. Int J Plasticity 2006;22:1265 
[29] Chaudhri MM, Acta Mater 1998;46:3047

[30] Durst K, Backes B, Goken M. Mater Res Soc Symp Proc 2005;841:311

[31] Alcala J, Casals O, Ocenasek J. J Mech Phy Solids 2008;56:3277

[32] Oliver WC, Pharr GM. J Mater Res 1992;7:1564

[33] Fischer-Cripps AC. Vacuum 2000;58:569

[34] Gong J, Miao H, Peng Z. Mater Lett 2004;58:1349

[35] Sawa T, Tanaka K, J Mater Res 2001;16:3084

[36] Martin M, Troyon M. J Mater Res 2002;17:2227

[37] Qiao XG, Starink MJ, Gao N. Mater Sci Eng A 2009;513:52

[38] Starink MJ, Qiao XG, Zhang J, Gao N. Acta Mater 2009;57:5796

[39] ASM handbook. Vol. 2, Properties and selection: nonferrous alloys and specialpurpose materials, tenth ed, ASM international. 1991

[40] Clausen B, Lorentzen T, Leffers T. Acta Mater 1998;46:3087

[41] Kissell JR, Ferry RL. Aluminium structures: a guide to their specifications and design, second ed, New York, John Wiley \& Sons, 2002

[42] Demir E, Raabe D, Zaafarani N, Zaefferer S. Acta Mater 2009;57:559

[43] McElhaney KW, Vlassak JJ, Nix WD. J Mater Res 1998;13:1300

[44] Poole WJ, Ashby MF, Fleck NA. Scripta Mater 1996;34:559

[45] Estrin Y, Molotnikov A, Davies CHJ, Lapovok R. J Mech Phy Solids 2008;56:1186 